\title{
Experimental Analysis of Power Quality Issues in a Mobile House supplied by Renewable Energy Sources
}

\author{
Marco Beccali ${ }^{1}$, Massimiliano Luna ${ }^{1}$, Marcello Pucci $^{2}$ and Gianpaolo Vitale ${ }^{2}$ \\ ${ }^{1}$ D.R.E.AM. - Dipartimento di Ricerche Energetiche e Ambientali. \\ Università degli Studi di Palermo. Viale delle Scienze, Edificio 9. 90128 Palermo. Italy. \\ ${ }^{2}$ I.S.S.I.A.-C.N.R. Section of Palermo (Institute on Intelligent Systems for the Automation). \\ Via Dante, 12. 90141 Palermo. Italy. \\ phone: +39091-6113513; fax: +39091-6113028; email:vitale@pa.issia.cnr.it
}

\begin{abstract}
This paper presents the results of an experimental analysis performed on a renewable hybrid system in order to evaluate the power quality of its electrical power network, which can be influenced by three factors: the variations in the power supplied by renewable energies due to the meteorological conditions, the adopted inverter and its control strategy, which is very meaningful for the performance of the whole system, the presence of non linear loads, which in recent years have dramatically increased. The results of the experimental analysis of the power quality parameters are presented in detail and investigated also with regard to European technical standards.

The main parameters which have been investigated are: voltage and current total harmonic distortion, respectively THDV and THDI, voltage variations at fundamental frequency, the effect of insertion/disconnection (tripping) of inverters and flicker. They have been explained and compared with the requirements reported in the European power quality standards.
\end{abstract}

Key Words: power quality, stand alone system, renewable energies.

\section{Introduction}

The possibility to obtain electrical energy from renewable sources as photovoltaic and wind plants and to provide this energy, thanks to the development of power electronic converters, has allowed the design and construction of a small building which can be easily transported in a chosen location and quickly installed, known as "mobile house". It can be used as a temporary house in case of disasters (e.g. earthquakes) or as a summer house, either alone or in a group or connected in a microgrid configuration.

Several solutions are available in the market but they all can be still optimized. In general these products are assembled using commercial equipments (the inverter and the loads) which are, each on its own, in compliance with their related standards.

In this framework single phase grid connected systems have been used for power levels up to $5 \mathrm{~kW}$, typically installed nearby customers [1]. The impact of these plants on the quality supplied to the customers can be influenced by three factors: the variations in the available power supplied by renewable energies due to the meteorological conditions; the adopted inverter and its control strategy, which is very meaningful for the performance of the whole system; the presence of non linear loads, which in recent years have dramatically increased [2]. Technical standards give the power quality requirements but usually for grid connected generation systems. In any case, it should be noted that the compliance of the inverter and the loads to the standards does not guarantee that they have a satisfactory behaviour in a local grid, moreover the standards often define the characteristic parameters referring to rated conditions.

For these reasons the characterization of both the generation system and the load in different working conditions is interesting.

\section{Characteristics of the plant under study}

A prototype of a mobile house, produced by Aster Consult s.r.l., has been used as experimental rig.

This prototype has a $20 \mathrm{~m}^{2}$ area and it has been installed on the roof at D.R.E.AM. (Dipartimento di Ricerche Energetiche e Ambientali), University of Palermo (Italy).

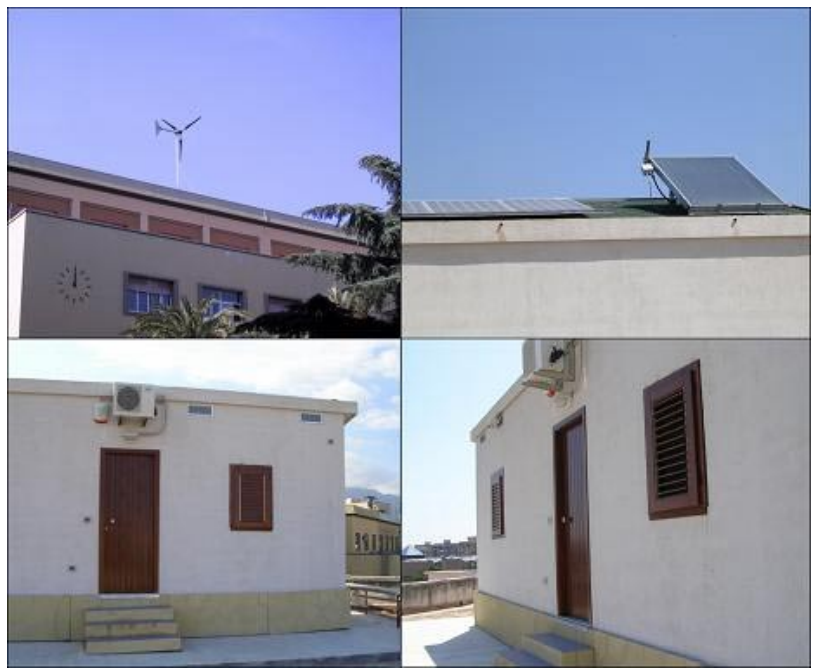

Fig. 1. The mobile house, the wind microturbine and the PV field. 


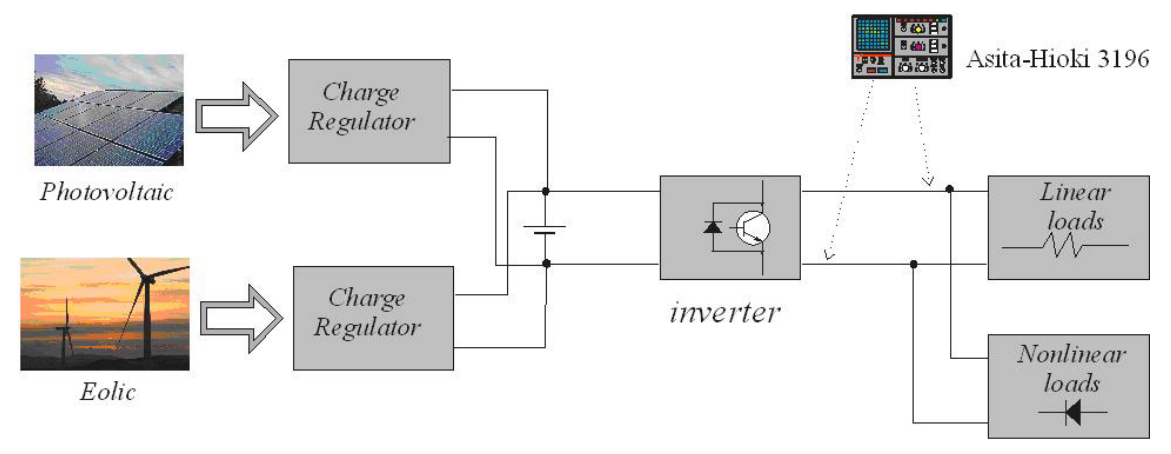

Fig. 2. Schematics of the electrical plant of the mobile house

The house is equipped with a PV field, made of 8 $\mathrm{m}-\mathrm{Si}$ modules with an $11 \mathrm{~m}^{2}$ area and a peak power of $1,2 \mathrm{~kW}$, South faced and tilted at $11^{\circ}$. The electrical storage system consists of lead-acid batteries with a capacity of $803 \mathrm{Ah}$ at $24 \mathrm{~V}$, with a 50 A charge regulator, and it feeds a $2700 \mathrm{VA}$ stand-alone single phase inverter. A wind microturbine has been set up and connected through its own charge regulator to the same batteries to enhance the electrical production and to realize a hybrid generation system. It has a peak power of $1 \mathrm{~kW}$ at $13,5 \mathrm{~m} / \mathrm{s}$ wind speed. Figure 2 shows the schematics of the electrical plant of the mobile house.

A series of measurements has been performed by means of an experimental set-up, which can be operated remotely via an Internet connection. Three electronic boards have been realized and interfaced to a purposely devised virtual instrument (Labview) in order to turn off/on various electric loads automatically and to acquire the most significant electric signals by means of Hall sensors.

In a previous work [3] the real performances of the system in relation to the total estimated consumption of the users and to the specific site have been evaluated, proposing suggestions and corrective measures.

In this work the power quality of its internal net has been analysed. A power quality analyser model AsitaHIOKI 3196 has been utilized, which is able to acquire four voltage channels with frequency (sampling rates) up to $2 \mathrm{Ms} / \mathrm{s}$.

This analyser allows to measure the r.m.s. values of voltage and current, frequency, power factor, as well as active, reactive and apparent power; it computes also the voltage and current THD and the amplitudes of the harmonics, expressed in percent of the fundamental. It is able to detect dips and swells, as well as to compute the flicker.

\section{Power quality issues}

Power quality is determined in the European standard CEI EN 50160 "Voltage characteristics of electricity supplied by public distribution systems" by voltage and frequency variations, frequency harmonics of voltage and current, flicker [4]. This standard refers to public distribution systems so it is not suitable to stand-alone PV systems, however since the loads have been designed and tested for grid supply in compliance with the technical standard, this standard is useful as a reference for islanded system analysis.

Each load has been characterized on the basis of the standard CEI EN 61000-3-2 "Electromagnetic compatibility (EMC) part 3, limits: section 2: limits for harmonic current emissions (equipment input current $\leq 16$ A per phase)" [5].

The parameter that describes the voltage distortion is the total harmonic distortion $\left(\mathrm{THD}_{\mathrm{V}}\right)$ defined as:

$$
T H D_{V}=\sqrt{V_{2}^{2}+V_{3}^{2}+\ldots+V_{n}^{2}} / V_{1}
$$

where $\mathrm{V}_{1}, \mathrm{~V}_{2}, \ldots, \mathrm{V}_{\mathrm{n}}$ are the harmonic r.m.s. values.

The European standard CEI EN 50160 provides a limit for the Total Voltage Harmonic Distortion equal to $8 \%$, including up to the $40^{\text {th }}$ harmonic. Moreover, limits for individual voltage harmonic are specified.

The parameter that describes the current distortion of the PCU (Power Conversion Unit) is the total harmonic distortion $\left(\mathrm{THD}_{\mathrm{I}}\right)$ defined as:

$$
T H D_{I}=\sqrt{I_{2}^{2}+I_{3}^{2}+\ldots+I_{n}^{2}} / I_{1}
$$

where $I_{1}, I_{2}, \ldots, I_{n}$ are the harmonic r.m.s. values.

The European standard CEI EN 61000-3-2 provides technical recommendations about power quality, and suggests design target for harmonic limits as shown in table I.

The standard CEI EN 61727 "Photovoltaic (PV) systems. Characteristics of the utility interface" claims that low levels of current and voltage harmonics are desirable. Suggested design target for harmonic limits, required by the standard, is 5\% for Total Harmonic Distortion of current. This prescription is generally applied at the peak output rating of the system [6].

The standard CEI EN 50160 defines the voltage variation as an increase (swell) or decrease (dip) of voltage normally due to variation of total load of a distribution system or a part of it. "Under normal operating conditions, excluding voltage interruptions, during each period of one week the $95 \%$ of the $10 \mathrm{~min}$. mean rms values of supply voltage should be in the range of $U_{N} \pm 10 \% U_{N} "$.

The overvoltage of the fundamental is due to the current at fundamental frequency generated by the inverter that flows in the grid impedance. 
TABLE I. - Suggested design targets for harmonic limits

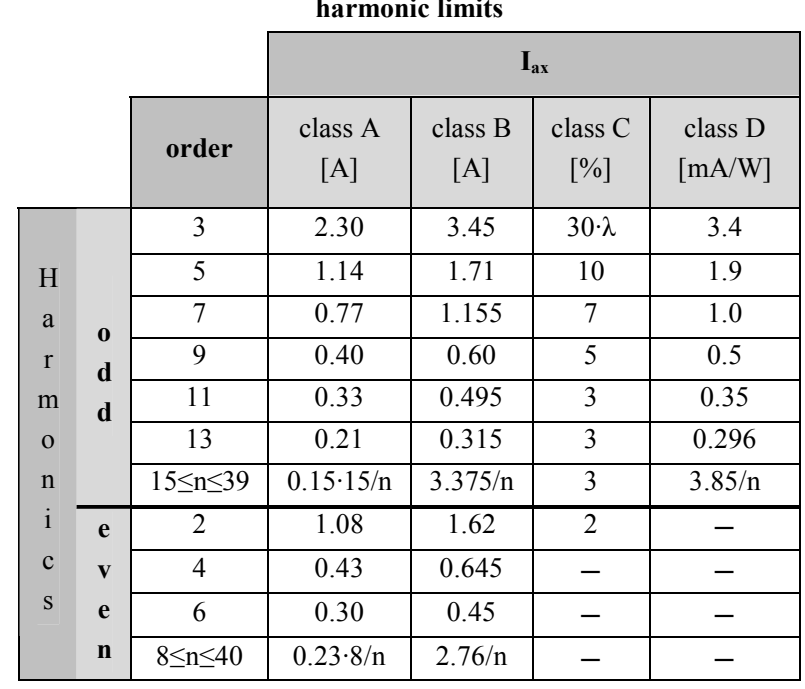

Due to the current variations generated by the PV plant (i.e. in presence of variable weather), voltage fluctuations may take place in the PCC (Point of Common Coupling). The voltage variations/fluctuations combined with "natural" voltage variations can cause repeatedly the trips of the overvoltage protection and the disconnection/reconnection from the network. This phenomenon causes also flicker as defined in the European standard CEI EN 50160: "The impression of unsteadiness of visual sensation induced by a light stimulus whose luminance or spectral distribution fluctuates with time".

The European standard CEI EN 50160 claims that, under normal operating conditions, for a system without a synchronous connection to an interconnected system the average value of the fundamental frequency, measured in a 10 seconds time slot, should be in the range $50 \mathrm{~Hz} \pm 2 \%$ during the $95 \%$ of a week.

\section{Results of power quality assessment}

\section{A. Loads characterisation}

For all the parameters investigated, even if the standards define requirements referred to the rated power of the inverter, the analysis has taken into account loads from $10 \%$ to $100 \%$ of rated power because the solar and wind production, as well as the loads, change during the day when the inverter is running.

With reference to the loads, they have been divided into linear and nonlinear ones. Linear loads have ohmic or ohmic-reactive behaviour and can be identified on the basis of the power required to the grid. On the contrary nonlinear loads require a periodic but nonsinusoidal current, their characterisation has been performed using the frequency analysis. For each of those loads the time profile of current, voltage and current spectra obtained by FFT are shown in figures from 3 to 7 . These data have been obtained by connecting to a external distribution grid which has a THDV equal to $2,98 \%$ at no load, as shown in fig. 8, in compliance to the standard [4]. They are summarized in tables II and III and the current harmonic values for the non linear loads are shown in Appendix 1.A.

\begin{tabular}{|c|c|c|}
\hline \multicolumn{2}{|c|}{ TABLE II. - Linear loads } \\
\begin{tabular}{|c|c|c|}
\hline $\begin{array}{c}\text { Incandescent } \\
\text { bulb }\end{array}$ & $100 \mathrm{~W}$ & Class \\
\hline $\begin{array}{c}2 \text { incandescent } \\
\text { bulbs }\end{array}$ & $600 \mathrm{~W}$ & $\mathrm{C}$ \\
\hline Electric stove & $1000 \mathrm{~W}$ & $\mathrm{~A}$ \\
\hline Hair-dryer & $600 \mathrm{~W}$ & $\mathrm{~A}$ \\
\hline
\end{tabular}
\end{tabular}

TABLE III. - Non linear loads

\begin{tabular}{|c|c|c|c|}
\hline Load & $\boldsymbol{P}_{\boldsymbol{N}}$ & Fig. & Class \\
\hline $\begin{array}{c}\text { 2 electronic discharge } \\
\text { lamps }\end{array}$ & $\begin{array}{c}48 \mathrm{~W} \\
\cos \varphi=0,65\end{array}$ & 3 & $\mathrm{C}$ \\
\hline 14" TV & $70 \mathrm{~W}$ & 4 & $\mathrm{D}$ \\
\hline PC and monitor & $370 \mathrm{~W}$ & 5 & $\mathrm{D}$ \\
\hline $\begin{array}{c}\text { Hair-dryer (at half rated } \\
\text { power) }\end{array}$ & $300 \mathrm{~W}$ & 6 & $\mathrm{~A}$ \\
\hline Heat pump & $1000 \mathrm{~W}$ & 7 & $\mathrm{~A}$ \\
\hline
\end{tabular}

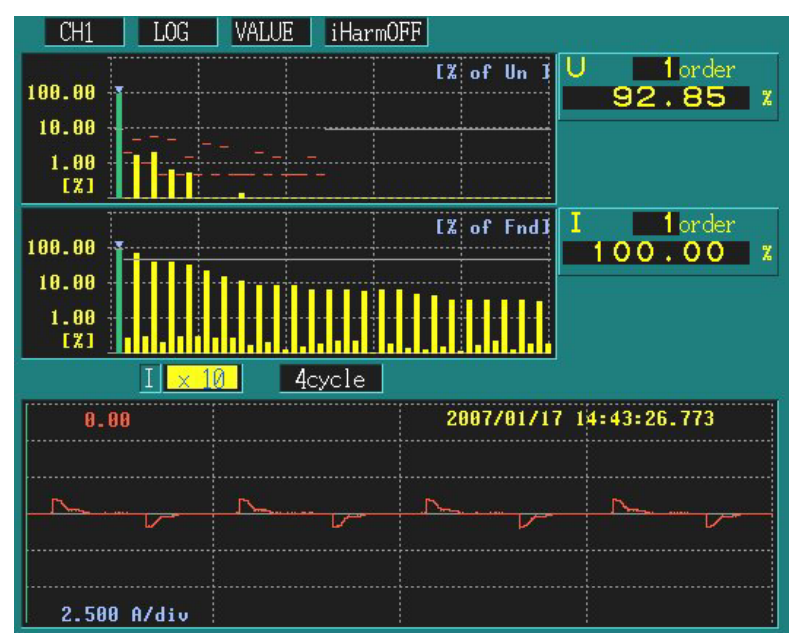

Fig. 3. Current waveform and voltage and current spectra for two electronic discharge lamps

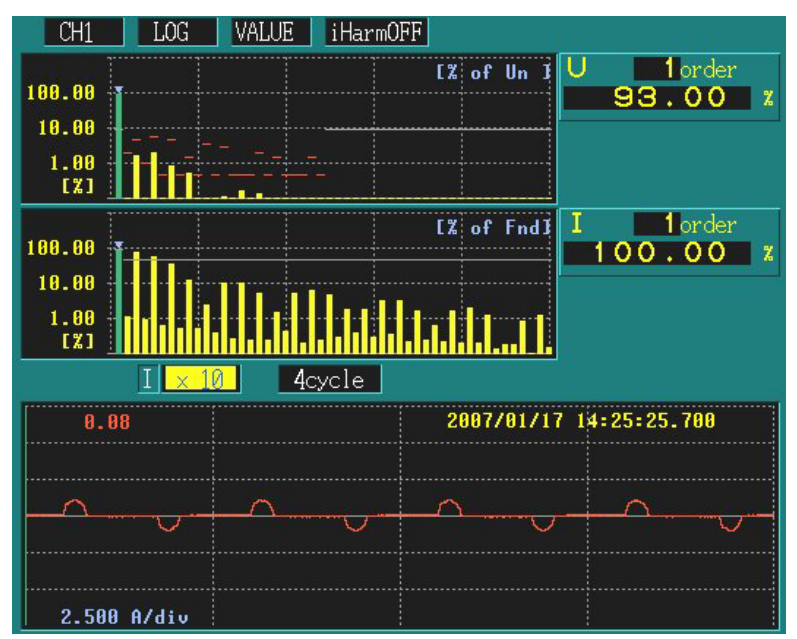

Fig. 4. Current waveform and voltage and current spectra for the 14 " TV 


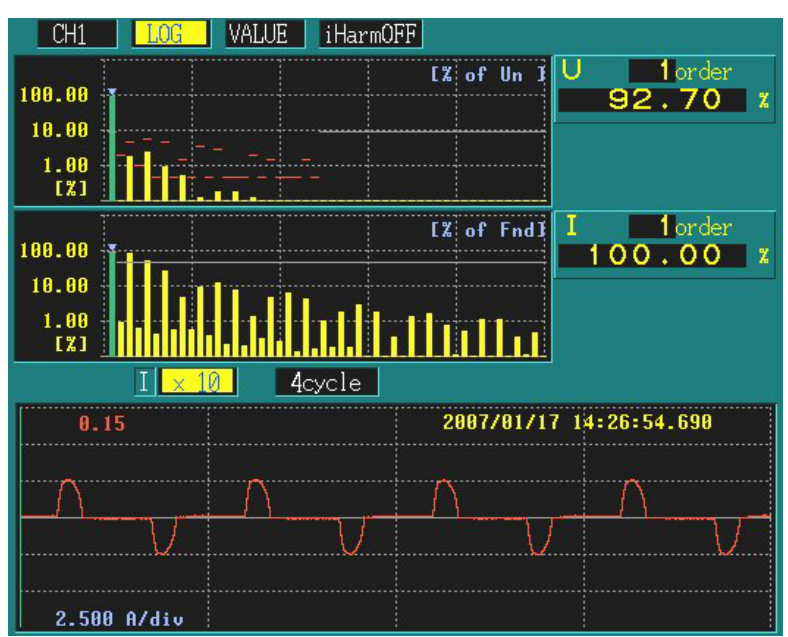

Fig. 5. Current waveform and voltage and current spectra for the PC and its monitor

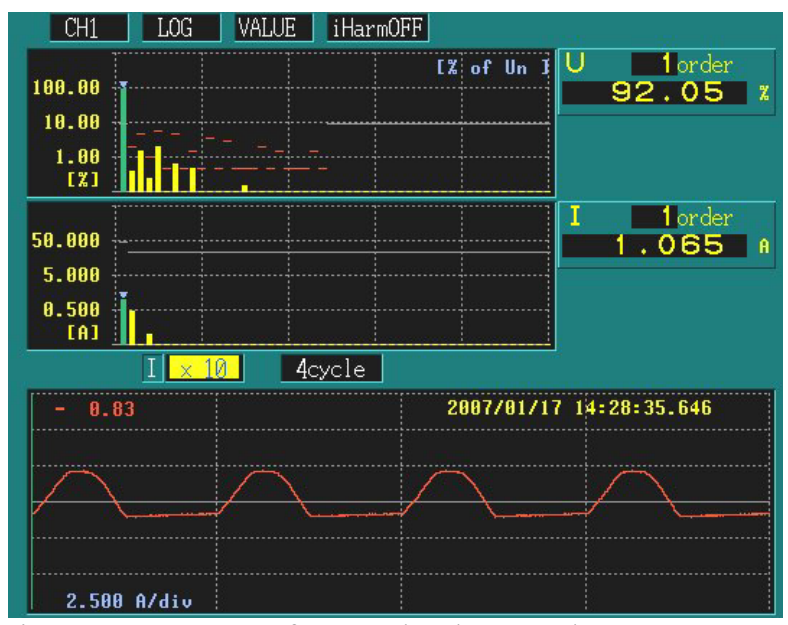

Fig. 6. Current waveform and voltage and current spectra for the hair-dryer at half rated power

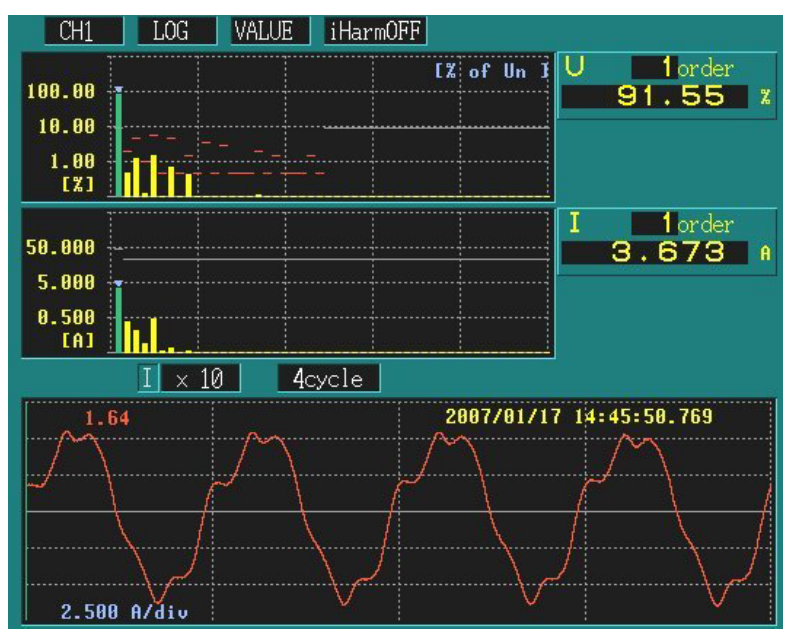

Fig. 7. Current waveform and voltage and current spectra for the heat pump

As a general comment, the presence of nonlinear loads causes a slight increase of the $\mathrm{THD}_{\mathrm{V}}$ which is always under $3,5 \%$ around $3 \%$, that is in compliance with the standard [4]. A singular case is the heat pump whose effect is to slightly reduce the $\mathrm{THD}_{\mathrm{V}}$. As far as an harmonic by harmonic analysis is concerned [5], it should be noted that sometimes certain harmonics loads

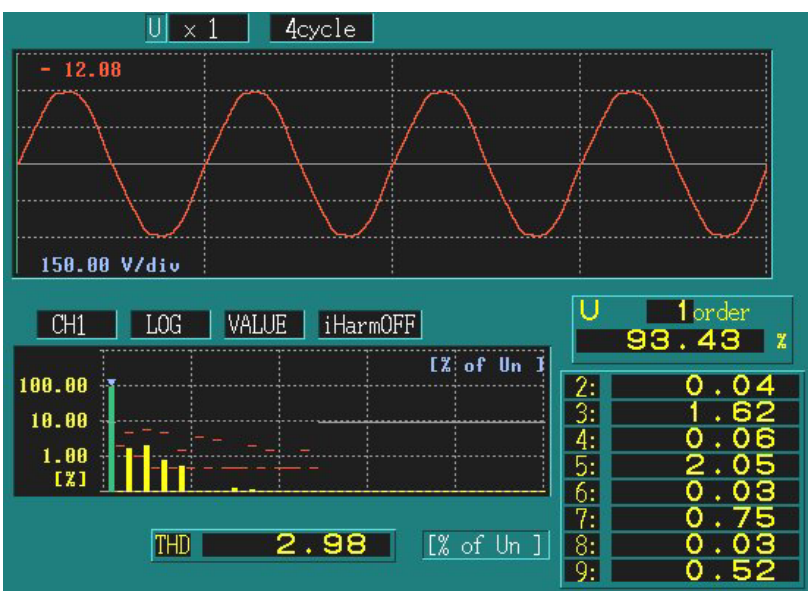

Fig. 8. Voltage waveform and spectrum, main harmonics and $\mathrm{THD}_{\mathrm{V}}$ of the real grid at no load

are out of the prescribed limits. In average the effect is worse for very low power loads. On the contrary the $\mathrm{THD}_{\mathrm{I}}$ is always very high with its minimum value of $18,6 \%$ obtained with the heat pump. In any case for each nonlinear load the $\mathrm{THD}_{\mathrm{I}}$ is always above the standard limit [6].

TABLE IV. - Interaction between the local grid and the loads configurations

\begin{tabular}{|c|c|c|c|c|}
\hline Loads & $\begin{array}{l}\text { Rated } \\
\text { Power }\end{array}$ & $T H D_{V}$ & $T H D_{I}$ & $\begin{array}{l}\text { Voltage } \\
\text { harmonics } \\
\text { exceeding the } \\
\text { limits }\end{array}$ \\
\hline $\begin{array}{c}2 \text { electronic } \\
\text { discharge lamps }\end{array}$ & $48 \mathrm{~W}$ & $3,83 \%$ & $114,19 \%$ & $12,14,15$ \\
\hline $14 " \mathrm{TV}$ & $70 \mathrm{~W}$ & $3,66 \%$ & $121,92 \%$ & 15 \\
\hline $\begin{array}{l}\text { Hair-dryer at } 1 / 2 \\
\text { rated power }\end{array}$ & $250 \mathrm{~W}$ & $2,69 \%$ & $46,07 \%$ & 6 \\
\hline $\mathrm{PC}$ and monitor & $370 \mathrm{~W}$ & $4,43 \%$ & $113,40 \%$ & 15 \\
\hline $\begin{array}{c}2 \text { electr. } \\
\text { discharge lamps }+ \\
300 \mathrm{~W} \text { bulb }\end{array}$ & $348 \mathrm{~W}$ & $2,44 \%$ & $14,59 \%$ & - \\
\hline $\begin{array}{c}\text { Hair dryer at } 1 / 2 \\
\text { rated power }+ \\
300 \mathrm{~W} \text { bulb }\end{array}$ & $550 \mathrm{~W}$ & $2,16 \%$ & $20,37 \%$ & $\begin{array}{l}8,10,12,14, \\
15,16,18\end{array}$ \\
\hline $600 \mathrm{~W}$ bulbs & $600 \mathrm{~W}$ & $1,97 \%$ & $2,34 \%$ & - \\
\hline $\begin{array}{l}\text { Stove, PC and } \\
\text { monitor }\end{array}$ & $1370 \mathrm{~W}$ & $1,88 \%$ & $12,20 \%$ & \\
\hline $\begin{array}{l}\text { Heat pump }+ \\
\text { stove }\end{array}$ & $2000 \mathrm{~W}$ & $1,56 \%$ & $5,04 \%$ & - \\
\hline $\begin{array}{c}\text { Heat pump }+ \\
\text { stove }+600 \mathrm{~W} \\
\text { bulbs }\end{array}$ & $2600 \mathrm{~W}$ & $2,39 \%$ & $4,50 \%$ & - \\
\hline $\begin{array}{c}\text { Heat pump }+ \\
\text { stove }+600 \mathrm{~W} \\
\text { bulbs }+ \text { hair-dryer } \\
\text { at rated power }\end{array}$ & $3100 \mathrm{~W}$ & $5,57 \%$ & $10,36 \%$ & - \\
\hline
\end{tabular}

\section{B. Islanded system supplied by the internal grid: steady state analysis}

In the following the effects of various kind of loads on the local grid are shown, for power levels up to the rated power of the inverter. These data have been obtained by connecting to the local grid (supplied by the inverter) which has a $\mathrm{THD}_{\mathrm{V}}$ equal to $3,69 \%$ at no load and has some harmonics out of the prescribed limits in 
[4], as shown in fig. 9. The voltage measurement has been done at the PCC after the low-pass filter interconnecting the inverter with the internal grid as shown in figure 2 . All the tests have been done at steadystate and show the inverter current and voltage waveforms in the time domain, as well as their spectra obtained with the FFT (Fast Fourier Transform).

Several loads configurations, as shown in table IV, have been tested in terms of their impact on the PCC voltage by giving their associated $\mathrm{THD}_{\mathrm{V}}$. The interaction between the local grid and the loads configurations is described by reporting the $\mathrm{THD}_{\mathrm{I}}$ in table $\mathrm{V}$ and by representing the most meaningful voltage and current waveforms in figures $10 \div 13$. Voltage harmonic values are shown in Appendix 1.B.

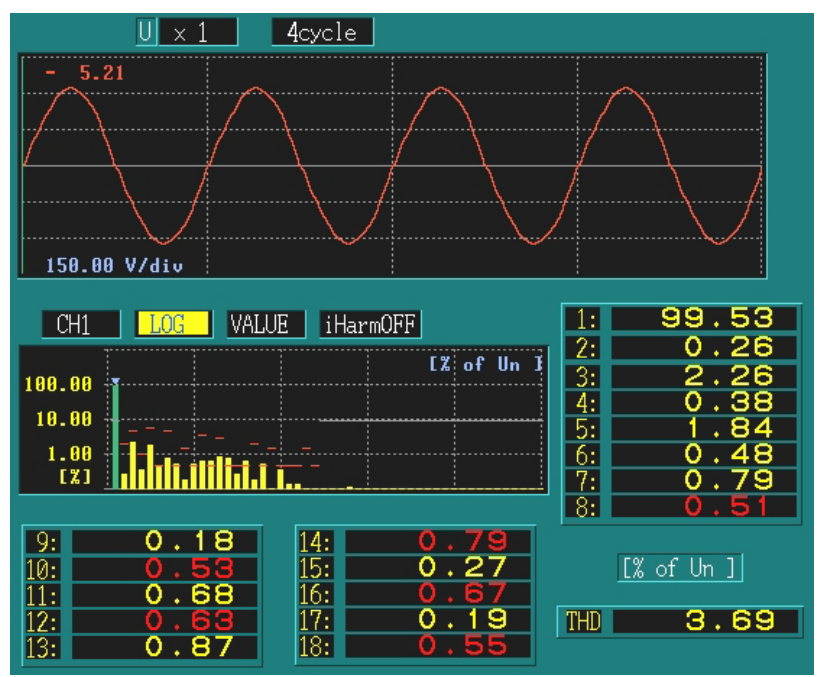

Fig. 9. Voltage waveform and spectrum, main harmonics and $\mathrm{THD}_{\mathrm{V}}$ of the local grid at no load

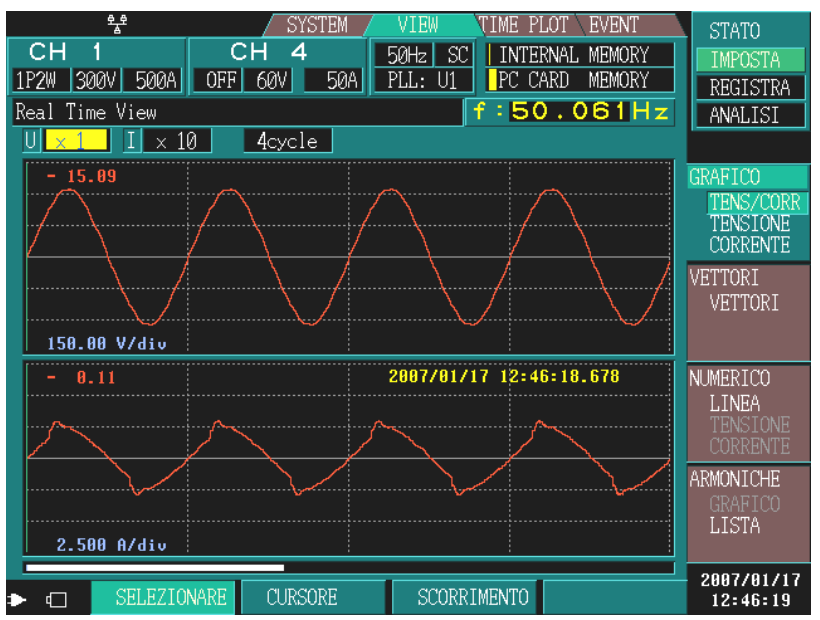

Fig. 10. Voltage and current in PCC for two electronic discharge lamps $+300 \mathrm{~W}$ bulb

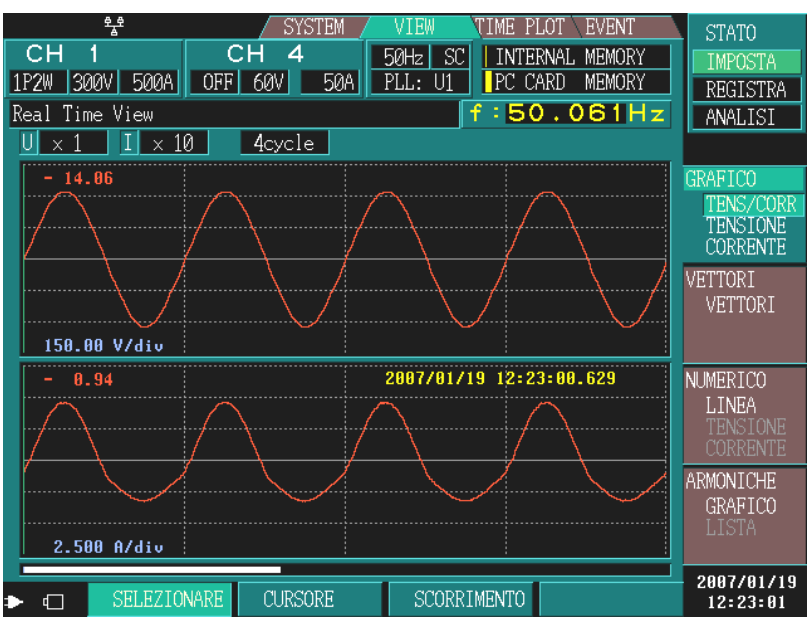

Fig. 11. Voltage and current in PCC for hair-dryer at $1 / 2$ rated power $+300 \mathrm{~W}$ bulb

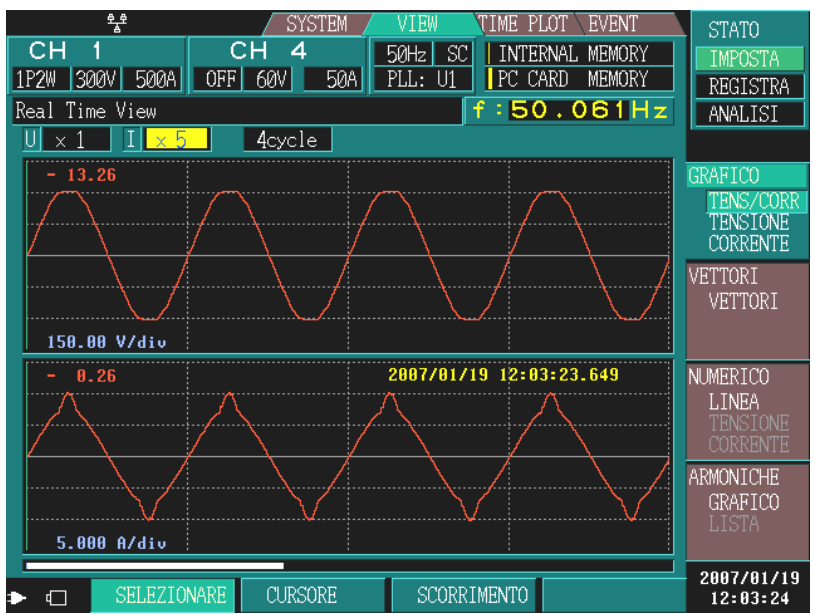

Fig. 12. Voltage spectrum in PCC for stove, PC and monitor

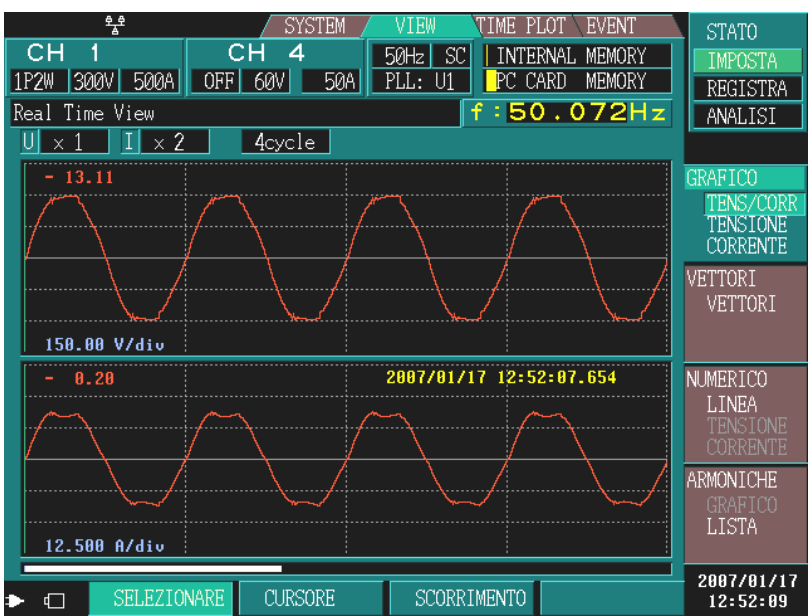

Fig. 13. Voltage and current in PCC for heat pump + stove $+600 \mathrm{~W}$ bulbs + hair-dryer at $1 / 2$ rated power

\section{Islanded system supplied by the internal grid: transient analysis}

It should be remarked that neither significative frequency variations nor flicker have been noticed. On the contrary, dips occur regularly during the commutations of the loads when the power increases by 
more than $500 \mathrm{~W}$. As an example, fig. 14 shows the voltage amplitude variation when the $600 \mathrm{~W}$ bulbs are connected from no load (-15,35\% dip). Similarly, fig. 15 shows the voltage amplitude variation when the same load has been connected and the heat pump and stove combination was already running (-13,45\% dip).

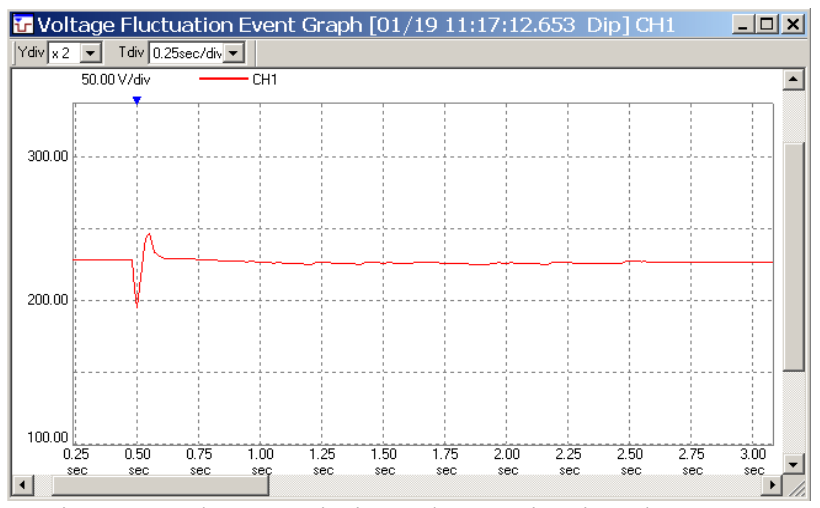

Fig. 14. Voltage variation when activating the $600 \mathrm{~W}$ bulbs from no load state.

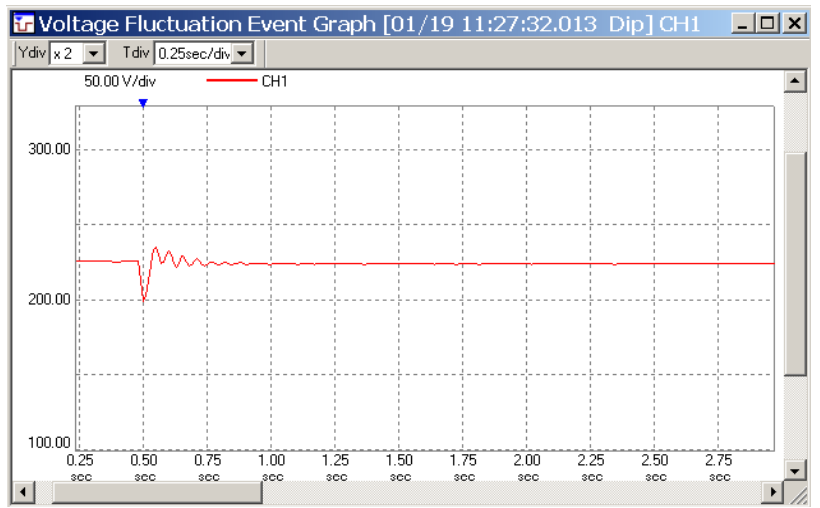

Fig. 15. Voltage variation when adding the same load to the heat pump and stove combination.

Moreover, it has been noticed that the connection of the heat pump causes a dip and swell sequence, as shown in fig. 16 (-24,34\% dip; $+13,65 \%$ swell).

None of these voltage variations, however, is so severe to cause the trips of the overvoltage protection and the disconnection/reconnection of the inverter.

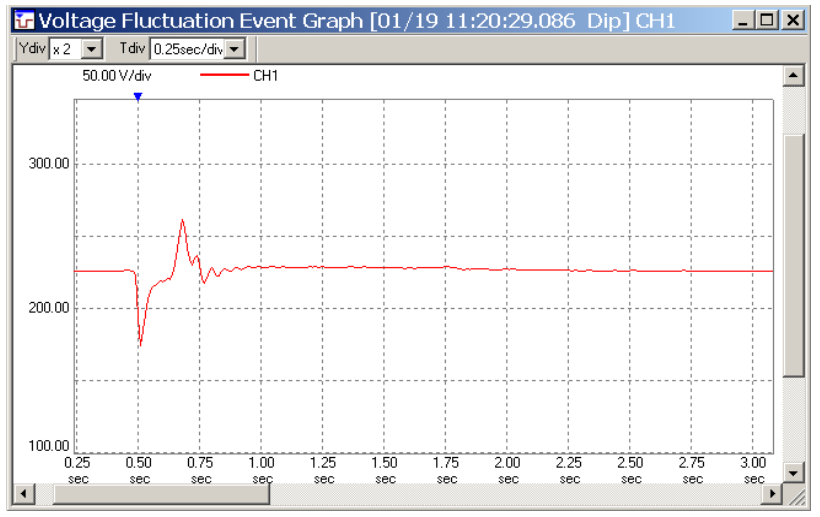

Fig. 16. Dip and swell sequence when activating the heat pump.

\section{Conclusions}

This paper presents the results of an experimental analysis performed on a renewable hybrid system (mobile house) in order to evaluate the power quality of its electrical power network.

It has been noticed that the presence of the battery storage system compensates the variability of the energy sources and has a low influence on the electrical power produced and its quality in terms of short interruptions and frequency variations. On the other hand, harmonic distortion has been noticed both on the voltage and on the injected current, as well as dips and swells. Even in such a small user, in fact, many non linear loads are present, like electronic equipments with switching power supplies and electronic discharge lamps, which are both disturbing and susceptible with regard to the power quality of the internal net. The most significative effect is on the harmonic content of the current, both in terms of single harmonics and $\mathrm{THD}_{\mathrm{I}}$ which very frequently overcomes the limits of the standard. This behaviour is reasonable since no particularly effective control techniques have been adopted for the inverter. Far better results have to be expected with voltage oriented control techniques. On the contrary no significative harmonic distortion has been highlighted in the voltage waveform at PCC for which the $\mathrm{THD}_{\mathrm{V}}$ is always within the standard limit and the single harmonics rarely exceed their limits.

\section{Acknowledgements}

This work has been conduced in the frame of a research contract funded by Aster Consult s.r.l. and by project of MIUR $n^{\circ} 211$.

\section{References}

[1] M. Calais, J. Myrik, T. Spooner, Vassilios G. Angelidis, "Inverters for Single-Phase Grid-Connected Photovoltaic Systems - An Overview", Power Electronics Specialist Conference, PESC 2002, IEEE 33rd Annual Conference, 23-26 June 2002.

[2] W. Mark Grady, S. Santoso, "Understanding Power System Harmonics", IEEE Power Engineering Review, November 2001.

[3] M. Beccali, M. Luna, G. Rizzo, G. Scaccianoce, G. Vitale, D. Barbieri, "Experimental investigation on a mobile house supplied via a hybrid PV and wind energy source", First International Renewable Energy Conference (IRES I), 3031 October 2006, Gelsenkirchen, Germany.

[4] European standard CEI EN 50160: "Voltage characteristics of electricity supplied by public distribution systems", 1994.

[5] European standard CEI EN 61000-3-2: "Electromagnetic compatibility (EMC) part 3, limits: section 2: limits for harmonic current emissions (equipment input current $\leq 16$ A per phase)", 1998 .

[6] European standard CEI EN 61727: "Photovoltaic (PV) systems. Characteristics of the utility interface", 1997. 


\section{Appendix 1}

A. Current harmonic values for non linear loads supplied by an external grid

(red ones are beyond the limits)

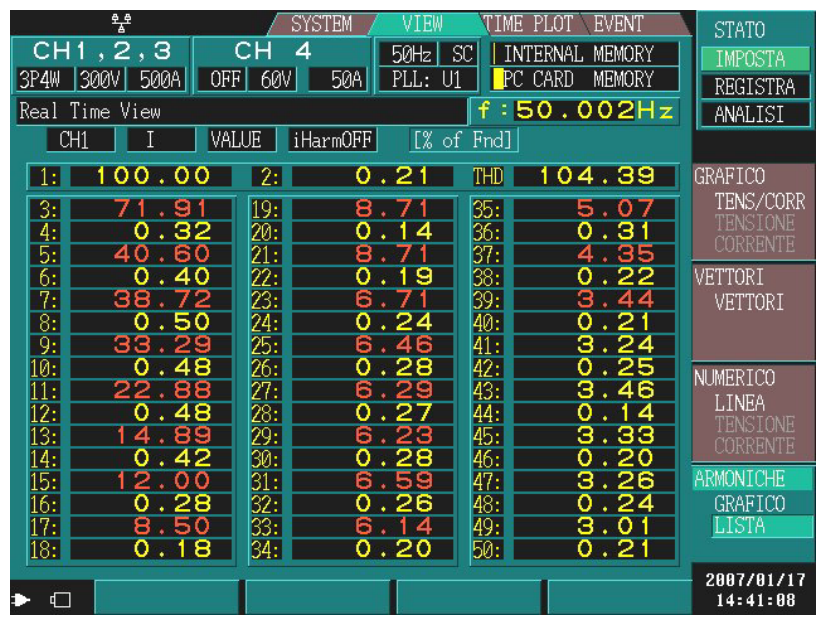

Fig. A1. Current harmonic values for two electronic discharge lamps

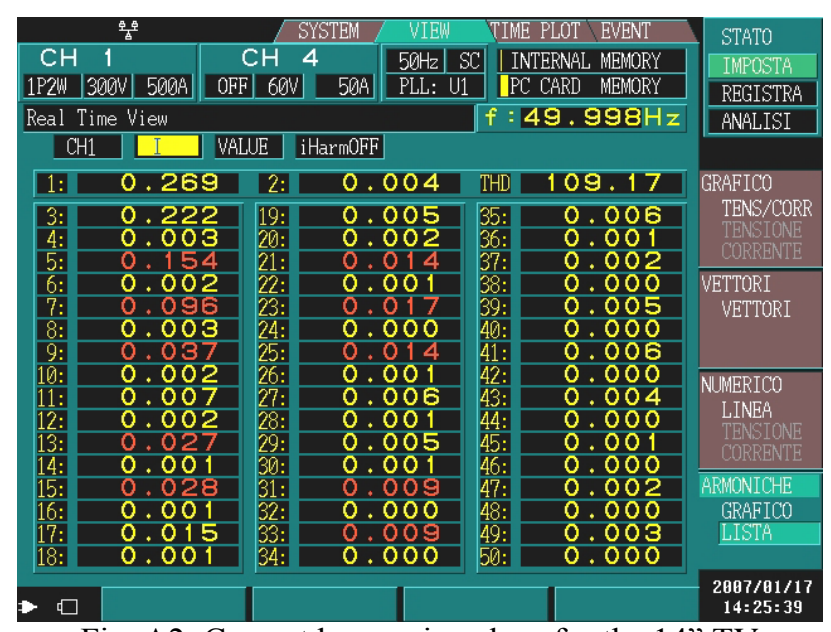

Fig. A2. Current harmonic values for the 14" TV

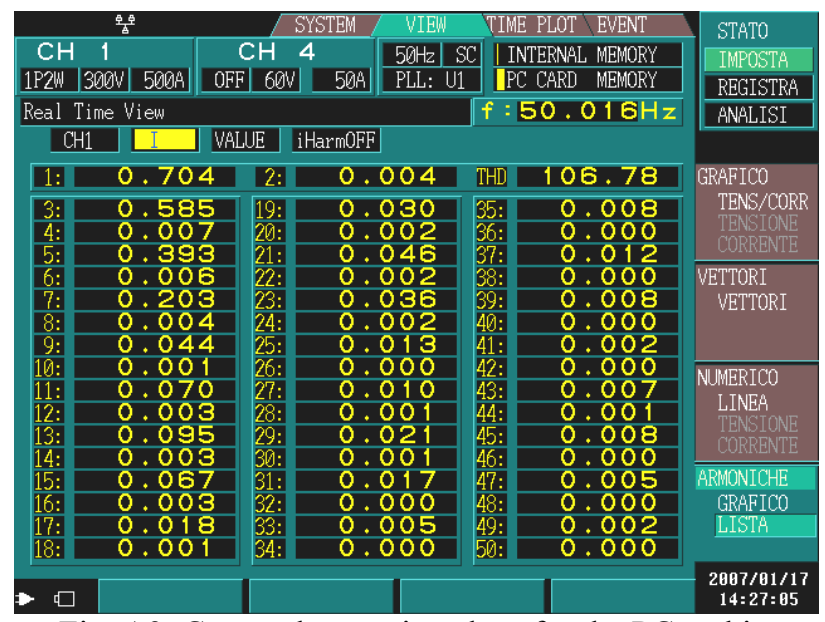

Fig. A3. Current harmonic values for the PC and its monitor

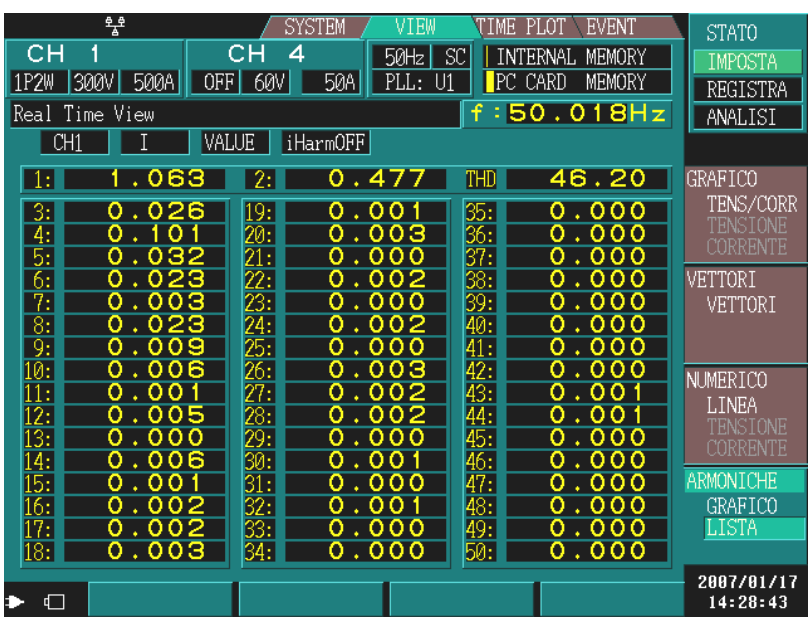

Fig. A4. Current harmonic values for the hair-dryer at half rated power

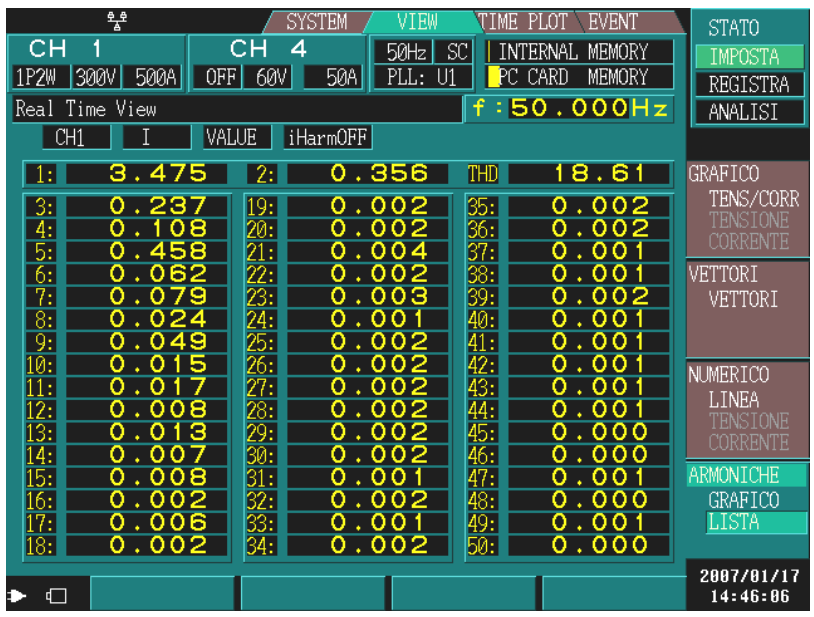

Fig. A5. Current harmonic values for the heat pump

B. Voltage harmonic values in islanded configuration

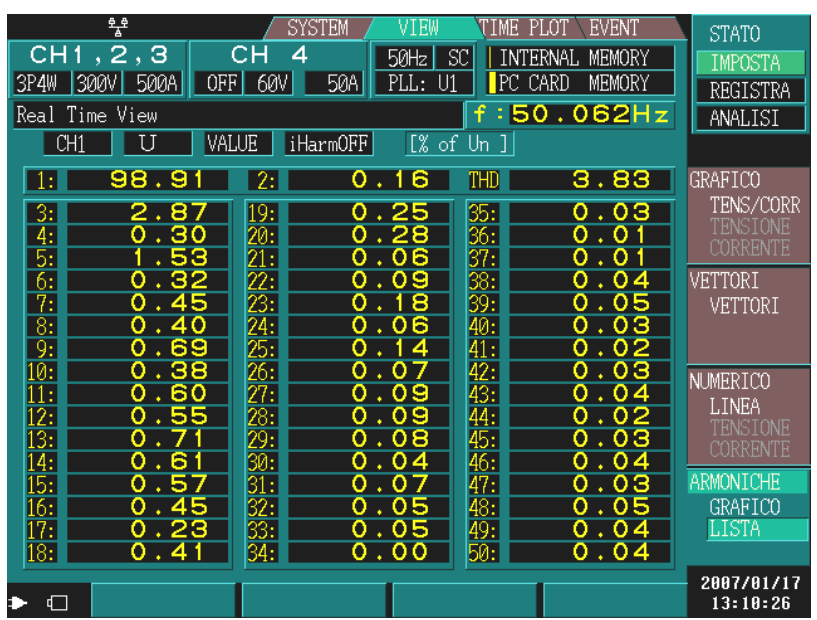

Fig. B1. Voltage harmonic values for two electronic discharge lamps 


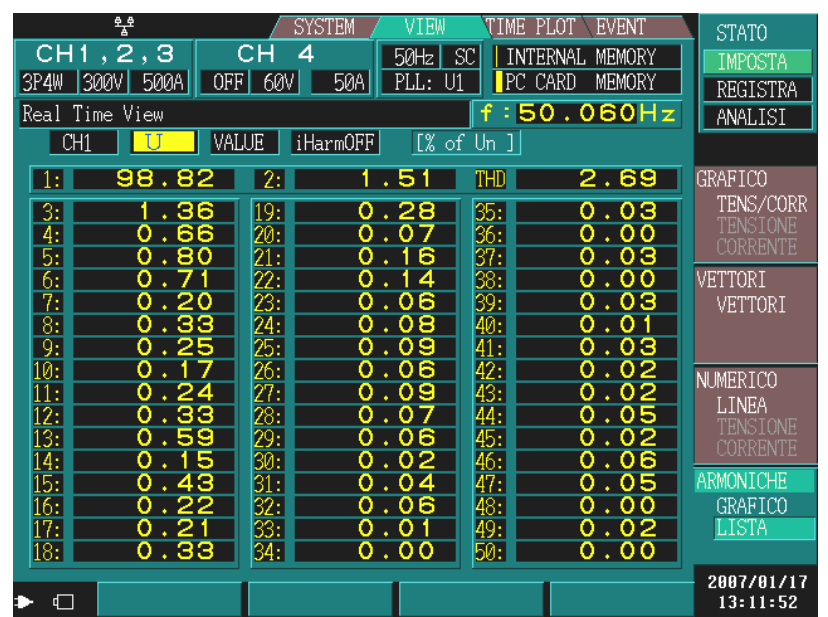

Fig. B2. Voltage harmonic values for the hair-dryer at half rated power

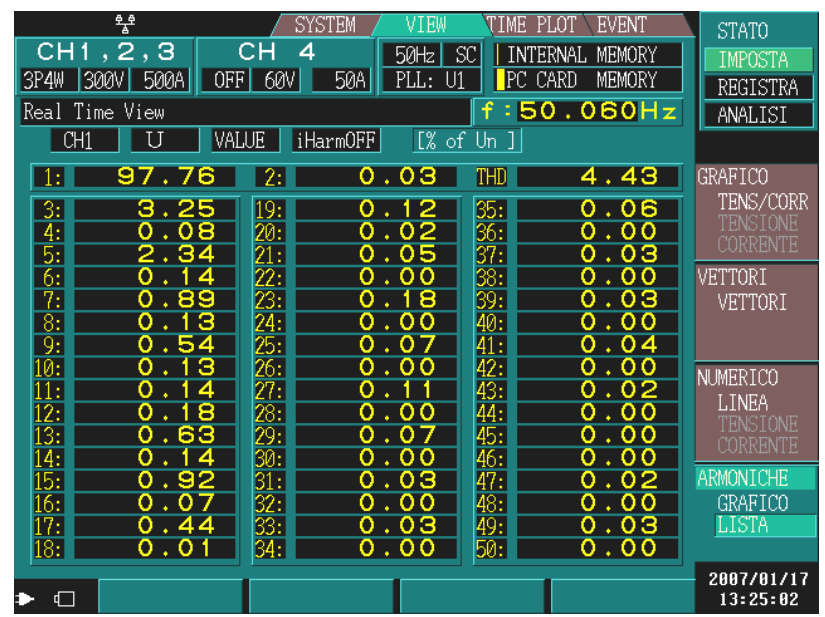

Fig. B3. Voltage harmonic values for the PC and monitor

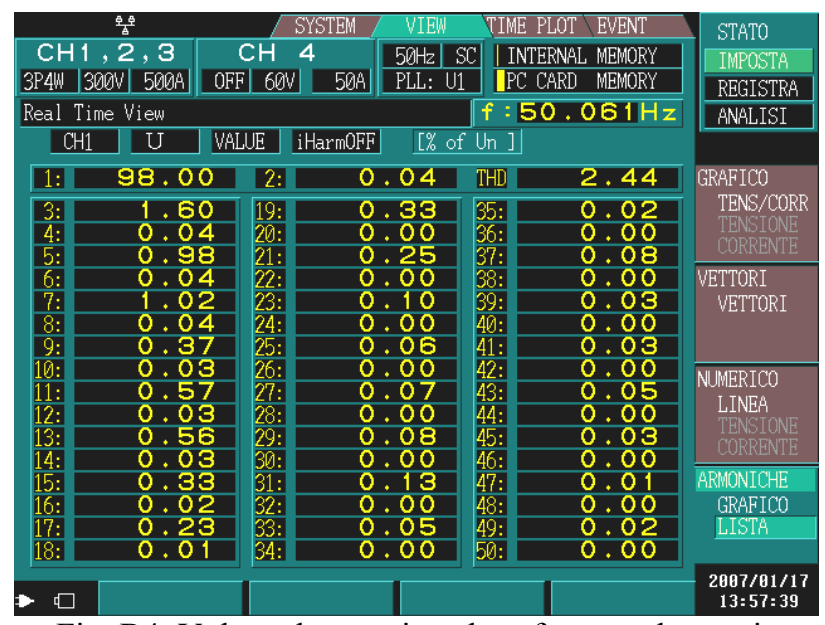

Fig. B4. Voltage harmonic values for two electronic discharge lamps $+300 \mathrm{~W}$ bulb

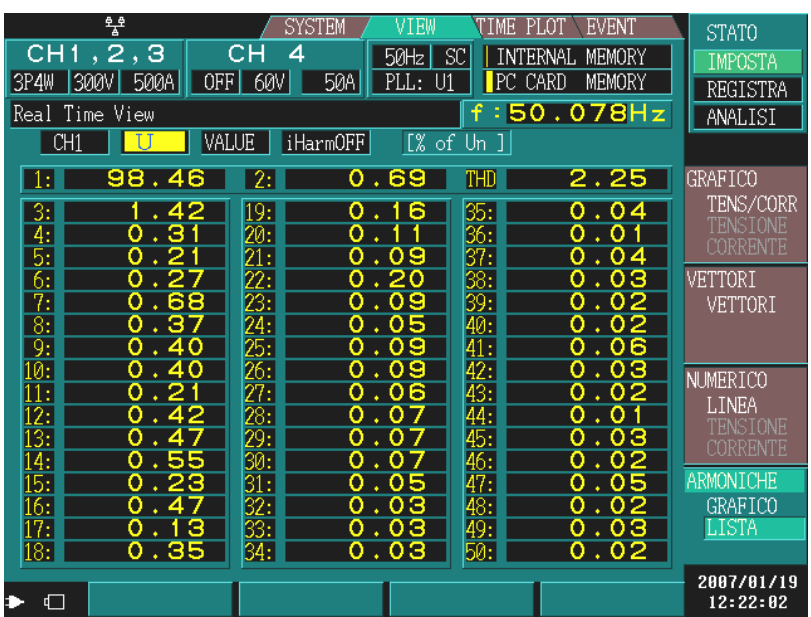

Fig. B5. Voltage harmonic values for the hair-dryer at $1 / 2$ rated power $+300 \mathrm{~W}$ bulb

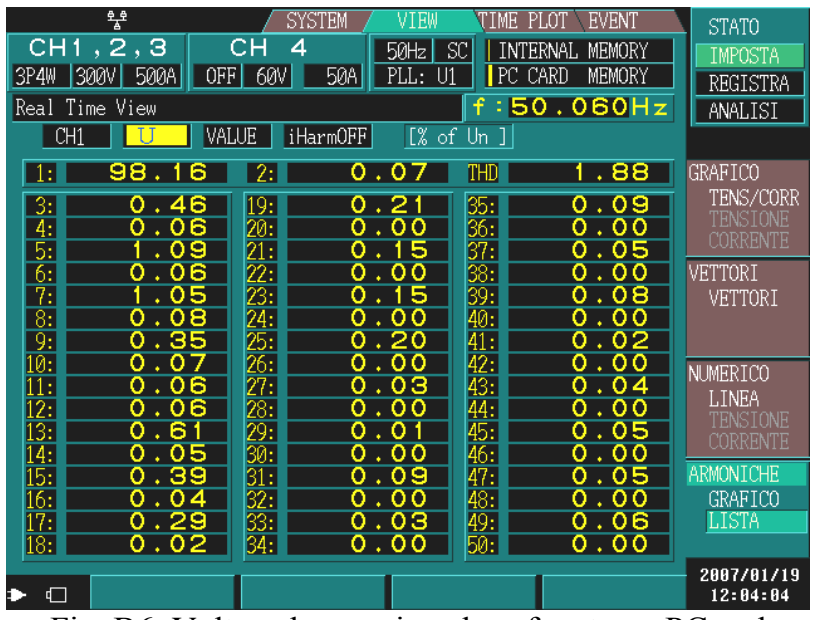

Fig. B6. Voltage harmonic values for stove, PC and monitor

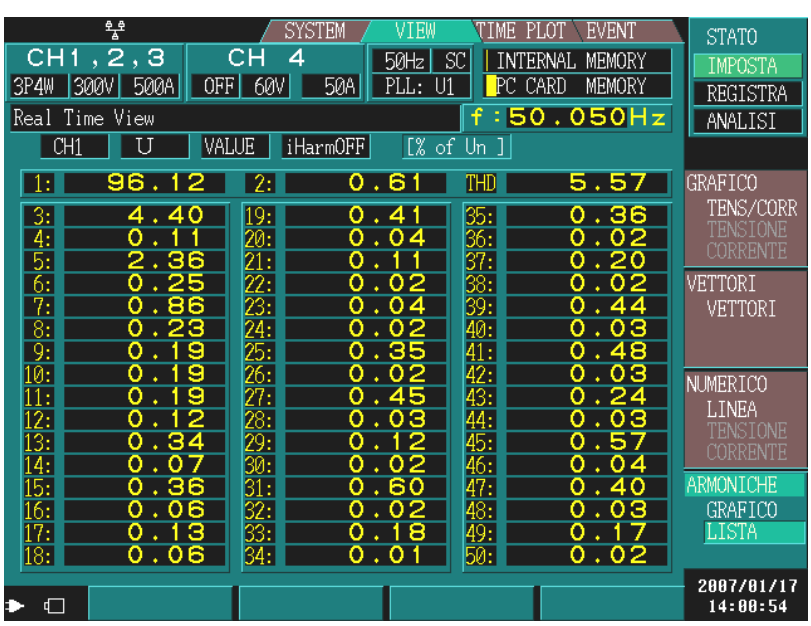

Fig. B7. Voltage harmonic values for heat pump + stove $+600 \mathrm{~W}$ bulbs + hair-dryer at $1 / 2$ rated power 